12,14

\title{
Анализ изменения концентрации фтора и водорода в результате химического дегидрофторирования поливинилиденфторида
}

\author{
(C) В.Е. Живулин ${ }^{1}$, В.М. Чернов ${ }^{2}$, А.А. Осипов ${ }^{3}$, М.В. Штенберг ${ }^{3}$, С.Е. Евсюков ${ }^{4}$, Л.А. Песин ${ }^{1}$ \\ ${ }^{1}$ Южно-Уральский государственный гуманитарно-педагогический университет, \\ Челябинск, Россия \\ 2 Челябинский государственный университет, \\ Челябинск, Россия \\ ${ }^{3}$ Институт минералогии УрО РАН, \\ Миасс, Россия \\ ${ }^{4}$ Evonik Industries AG, \\ Dossenheim, Germany \\ E-mail: Zhivulinve@mail.ru
}

(Поступила в Редакцию 19 апреля 2016 г.

В окончательной редакции 20 декабря 2016 г.)

Химическая карбонизация поливинилиденфторида необходима для синтеза на его основе квазиодномерных углеродистых структур, имеющих перспективу использования в микроэлектронике. Для уточнения деталей процесса карбонизации методами ядерного магнитного резонанса и инфракрасной спектроскопии измерены концентрации ядер ${ }^{19} \mathrm{~F}$ и ${ }^{1} \mathrm{H}$ и изучено изменение содержания $\mathrm{CF}_{2}-, \mathrm{CH}_{2}$ и ОН-групп в частично дегидрофторированных образцах поливинилиденфторида. Проведена оценка эффективности замещения атомов фтора и водорода ОН-группами в процессе дегидрофторирования полимерных цепей.

Работа выполнена в рамках государственного задания Министерства образования и науки РФ в сфере научной деятельности (НИР № 2531 „Синтез и свойства магнитоактивного слоя на поверхности пленки поливинилиденфторида (ПВДФ)“).

DOI: 10.21883/FTT.2017.07.44604.148

\section{1. Введение}

В последние годы большое число работ посвящено как практическому синтезу, так и теоретическому моделированию низкоразмерных углеродных структур, в том числе и карбина [1]. Карбин представляет собой совокупность углеродных цепей, в которых соседние атомы соединены между собой либо двойными, либо чередующимся тройными и одинарными связями. Существуют различные, зачастую противоречивые структурные модели карбиновых цепей и их взаимного упорядочения [2]. Однако обнаружение кристаллического карбина в природных минералах [3] вселяет надежду на реализацию условий его синтеза и в лабораторных условиях.

Одним из способов синтеза углеродистых материалов, содержащих одномерные фрагменты, является карбонизация галогенсодержащих полимеров [4,5]. Поливинилиденфторид (ПВДФ) - полимерный материал, обладающий рядом полезных свойств, благодаря которым он находит широкое применение в мембранных технологиях, электронике, медицине, акустике и т.д. Равное количество фтора и водорода в цепях создает потенциальную возможность использования ПВДФ в качестве исходного материала для создания одномерных углеродных наноструктур путем химического и/или радиационного дегидрофторирования (ДГФ). Согласно известной модели химической карбонизации, под влия- нием жидкой дегидрофторирующей среды фтор и водород в равных количествах отщепляются от углеродного каркаса и удаляются в виде молекул фтористого водорода $[4,6]$.

Ранее в работах [4,6-9] изучены процессы, происходящие при химической карбонизации ПВДФ. В [7] методом ИК-спектроскопии проведена оценка глубины и скорости проникновения дегидрофторирующей смеси в частично кристаллическую пленку Kynar. Анализировались вариации пиков поглощения с максимумами при 532 и $976 \mathrm{~cm}^{-1}$, возникающие вследствие колебаний $\mathrm{CF}_{2}-$ и $\mathrm{CH}_{2}$-групп соответственно. Сделан вывод об одинаковом уменьшении концентрации этих групп на различных стадиях процесса ДГФ, что подтверждает адекватность упомянутой выше модели.

С другой стороны, существует вероятность присоединения гидроксильных групп к освободившимся от фтора и водорода позициям в углеродной цепи, а также увеличения концентрации $\mathrm{CH}$-связей в образцах за счет протекания побочных реакций с водородсодержащими ингредиентами ДГФ-смеси. Поэтому интересной научной и практически важной задачей представляется изучение эволюции общего содержания фтора и водорода по мере протекания реакции ДГФ в продуктах химической карбонизации ПВДФ. Такую возможность предоставляет, например, метод ЯМР.

Описанные в $[8,9]$ изменения ЭПР поглощения при старении продуктов химической карбонизации ПВДФ 
при долговременном наблюдении демонстрируют существенную нестабильность их свойств. Поэтому важную роль приобретает поиск способов уменьшения эффекта старения. Одним из таких способов может оказаться термическая обработка. Логично ожидать, что при повышении температуры скорость всех деструктивных и релаксационных процессов в карбонизированной части полимера увеличится и стабилизация свойств наступит быстрее, чем при комнатной температуре. С другой стороны, термическое воздействие может вызвать дальнейшие структурные преобразования [10], в результате которых продукты химического ДГФ ПВДФ приобретут новые полезные свойства.

Таким образом, целью настоящей работы является изучение изменения концентрации фтора, водорода и содержащих эти элементы функциональных групп в зависимости от продолжительности реакции дегидрофторирования ПВДФ и влияния последующей термической обработки.

\section{2. Синтез образцов и методика измерений}

Объектами исследования были частично кристаллическая пленка ПВДФ марки Kynar (образец № 1) и пять образцов карбиноидных пленок, синтезированных из этого исходного полимера методом химического ДГФ при комнатной температуре в течение 1, 3, 7, 15 и $24 \mathrm{~h}$ (образцы № 2-6 соответственно). В течение $15 \mathrm{~h}$ одновременно синтезировались два образца, один из которых после ДГФ отжигался при температуре $270^{\circ} \mathrm{C}$ в течение $40 \mathrm{~min}$ (образец № 7).

Химическая карбонизация ПВДФ проводилась по методике, описанной в [4]. Для приготовления дегидрофторирующей смеси в стеклянную колбу наливали $30 \mathrm{ml}$ этилового спирта и добавляли $9 \mathrm{~g}$ едкого калия. Перемешивание производилось при помощи магнитной мешалки. Далее к получившемуся насыщенному раствору $\mathrm{KOH}$ в этаноле добавлялось $270 \mathrm{ml}$ ацетона. Полученная смесь в течение $30 \mathrm{~min}$ перемешивалась до приобретения равномерно коричневого цвета. Перед помещением пленок ПВДФ в смесь их промывали в ультразвуковой ванне последовательно в дистиллированной воде и ацетоне в течение $30 \mathrm{~min}$. Под воздействием ацетона пленки набухали, что впоследствии способствовало более эффективному проникновению смеси в объем полимера и его карбонизации. Продолжительность ДГФ отсчитывалась с момента погружения образца в смесь. После изъятия образцов из смеси они снова промывались в дистиллированной воде и ацетоне.

Термообработка образца № 7 производилась в трубчатой печи, оборудованной высокоточным регулятором температуры, в атмосфере воздуха. Погрешность измерения температуры не превышала $5^{\circ} \mathrm{C}$.

Спектры инфракрасного поглощения регистрировались на ИК-Фурье спектрометре Nicolet-6700 фир- мы Thermo Scientific в интервале волновых чисел $400-5500 \mathrm{~cm}^{-1}$ в геометрии на пропускание. В диапазоне 4500-5500 $\mathrm{cm}^{-1}$ во всех спектрах наблюдалась четкая интерференционная картина, позволившая определить оптическую толщину каждого образца. В интервале $2400-3700 \mathrm{~cm}^{-1}$ в спектрах образцов № 2-7 наблюдается широкая полоса поглощения, связанная с валентными колебаниями ОН-групп, которая отсутствует в спектре образца № 1. Полосы поглощения, обусловленные антисимметричными и симметричными колебаниями ОН-групп, при записи спектра на стандартных приборах средней дисперсии сливаются в одну широкую полосу, максимум которой расположен около $3400 \mathrm{~cm}^{-1}$ [11]. Анализ разностных спектров образцов № 2-7 и образца № 1 показал, что форма этой полосы в результате ДГФ не изменяется, а ее интенсивность возрастает с увеличением продолжительности реакции и существенно уменьшается при отжиге. Форма полос поглощения в области $740-820 \mathrm{~cm}^{-1}$ также не меняется, а их интенсивности уменьшаются с увеличением продолжительности химического воздействия. Стабильность формы позволила при выявлении количественных параметров спектров заменить измерения площадей полос поглощения $v \mathrm{OH}\left(2400-3700 \mathrm{~cm}^{-1}\right), \delta \mathrm{CF}_{2}+\delta \mathrm{CCC}$ $\left(765 \mathrm{~cm}^{-1}\right), r \mathrm{CH}_{2}\left(796 \mathrm{~cm}^{-1}\right)$ измерением их пиковых интенсивностей относительно базовой линии с последующей нормировкой на толщину образцов.

Измерения ЯМР производились на импульсном спектрометре, изготовленном в Казанском (Приволжском) федеральном университете. Резонансная частота составляла $25 \mathrm{MHz}$. Исследуемые пленочные образцы массой около $1 \mathrm{~g}$ плотно скручивались в рулон диаметром $7 \mathrm{~mm}$ и длиной $20 \mathrm{~mm}$ и помещались в стеклянную пробирку. Регистрировался спад свободной индукции (ССИ) по-

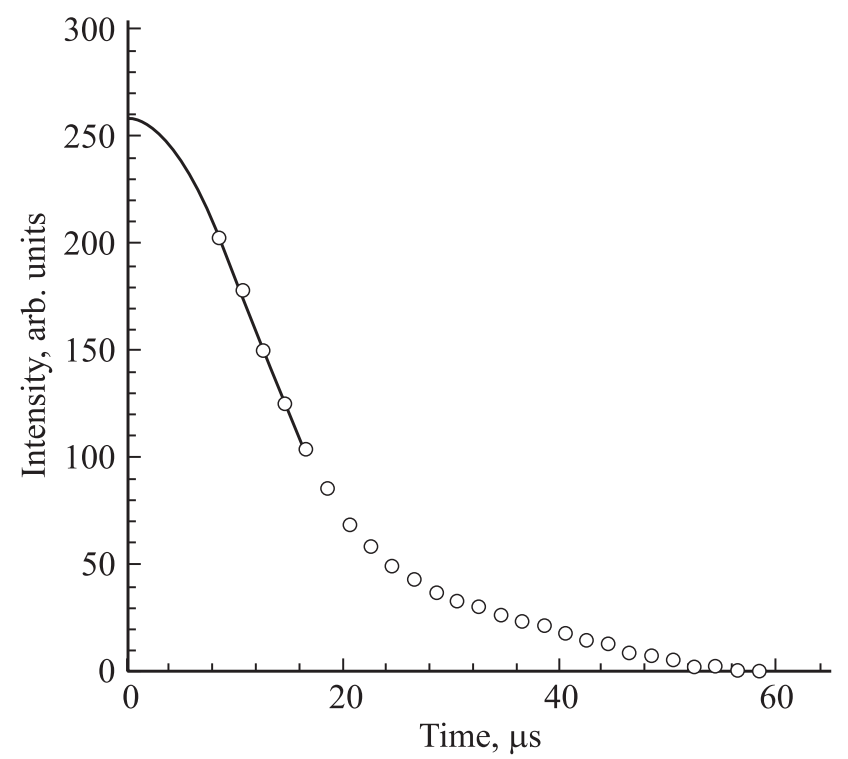

Рис. 1. Спад свободной индукции ядер $\mathrm{H}^{1}$ в образце № 1. Сплошной линией обозначена гауссова аппроксимационная кривая. 
сле $90^{\circ}$ импульса длительностью $3 \mu \mathrm{s}$. Время восстановления приемника после воздействия высокочастотного импульса составляло $6 \mu \mathrm{s}$. Измерялась интенсивность сигнала ССИ в зависимости от времени с дискретизацией $2 \mu \mathrm{s}$. ССИ имел форму, близкую к кривой Гаусса, типичную для твердых аморфных полимеров [12]. Для нахождения начальной амплитуды сигнала ССИ экстраполировался к нулевому моменту времени (середине $90^{\circ}$ импульса) с помощью гауссовой аппроксимации, как это показано на рис. 1.

Относительное содержание ядер водорода и фтоpa ${ }^{1} \mathrm{H} /{ }^{19} \mathrm{~F}$ вычислялось по формуле

$$
{ }^{1} \mathrm{H} /{ }^{19} \mathrm{~F}=I_{\mathrm{H}} \gamma_{\mathrm{F}}^{2} / I_{\mathrm{F}} \gamma_{\mathrm{H}}^{2},
$$

где $I_{\mathrm{H}}$ и $I_{\mathrm{F}}-$ нормированные на массу образцов интенсивности сигналов от ядер водорода и фтора соответственно, $\gamma_{\text {H }}$ и $\gamma_{\mathrm{F}}$ - гиромагнитные отношения ядер водорода и фтора соответственно.

По результатам измерений находились концентрации ядер ${ }^{1} \mathrm{H}$ и ${ }^{19} \mathrm{~F}$ в $1 \mathrm{~g}$ каждого из образцов.

\section{3. Результаты и обсуждение}

Общая форма ИК-спектров, соответствующая доминированию в образцах цепей $\alpha$-конформации, сохраняется при различных продолжительностях ДГФ и радикально изменяется лишь в результате дополнительного термического воздействия. На рис. 2 в качестве примера представлены ИК-спектры образцов № 1, 3 и 6 в диапазоне $400-1900 \mathrm{~cm}^{-1}$ (на этом рисунке, а также на рис. 3-5 спектры приведены в исходном виде без нормировки на толщину пленок). Несмотря на тенденцию фоновой составляющей поглощения к росту при увеличении продолжительности ДГФ, заметно уменьшение интенсивности всех пиков, особенно при 508 и $840 \mathrm{~cm}^{-1}$ (вставки на рис. 2), которые связаны с колебаниями молекул в $\beta$-фазе полимера [13]. Последний факт подтверждает вывод работы [14] о более высокой активности $\beta$-фазы ПВДФ в реакции ДГФ по сравнению с поведением $\alpha$-фазы. При сравнении ИК-спектров образцов с продолжительностью синтеза $15 \mathrm{~h}$, не подвергавшегося и подвергавшегося термообработке (образцы № 5 и 7), представленных на рис. 3, можно увидеть увеличение интенсивности обсуждаемых полос поглощения (вставки на рис. 3), что свидетельствует о термоиндуцированном конформационном превращении $\alpha \rightarrow \beta$ в той части полимерного вещества, которая не прореагировала со смесью после ДГФ в течение $15 \mathrm{~h}$. В то же время все полосы поглощения, связанные с цепями $\alpha$-типа, после термического воздействия существенно ослабляются. Появление наплывов вблизи 600 и $740 \mathrm{~cm}^{-1}$ связано c частичной аморфизацией кристаллических областей $\alpha$-типа [13]. Эти эффекты видны при сравнении спектров образцов № 5 и 7, представленных на рис. 3.

Основные изменения формы ИК-спектров ПВДФ в результате дегидрофторирования происходят в интерва-
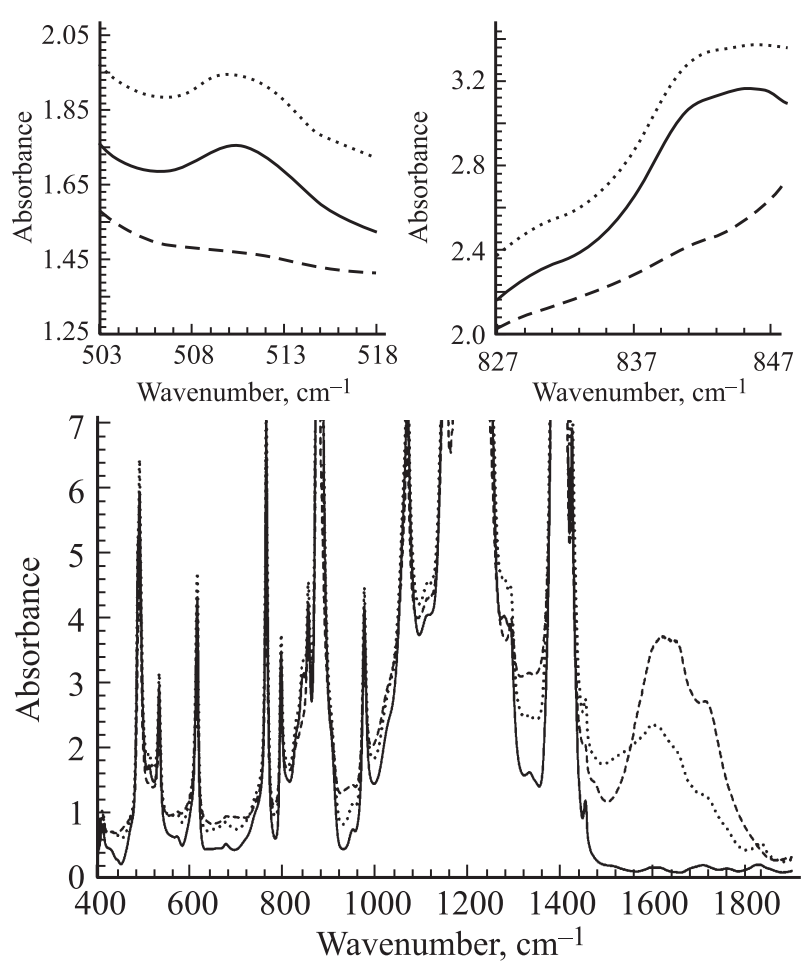

Рис. 2. ИК-спектры поглощения образцов № 1,3 и 6 (сплошная, пунктирная и штриховая линии соответственно) в интервале $400-1900 \mathrm{~cm}^{-1}$. Здесь, а также на рис. 3-5 спектры приведены в исходном виде без нормировки на толщину пленок.
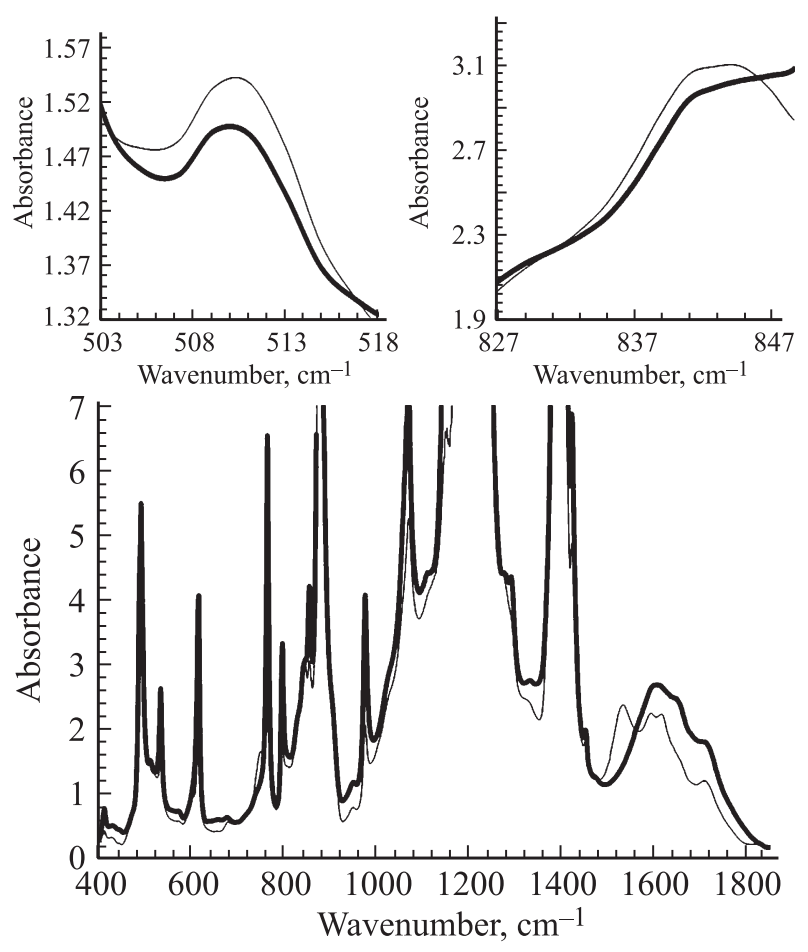

Рис. 3. ИК-спектры поглощения образцов № 5 и 7 (жирная и тонкая сплошные линии соответственно) в интервале $400-1900 \mathrm{~cm}^{-1}$. 


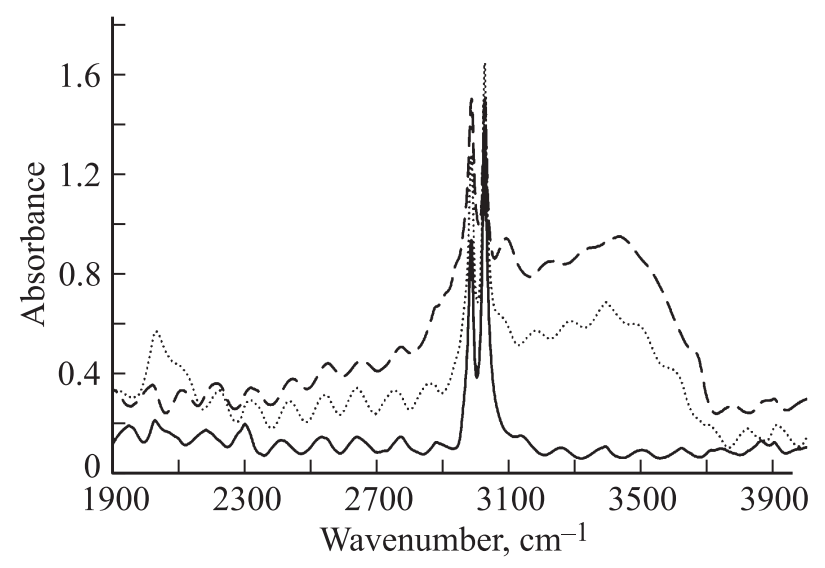

Рис. 4. ИК-спектры поглощения образцов № 1,3 и 6 (сплошная, пунктирная и штриховая линии соответственно) в интервале $1900-4000 \mathrm{~cm}^{-1}$.

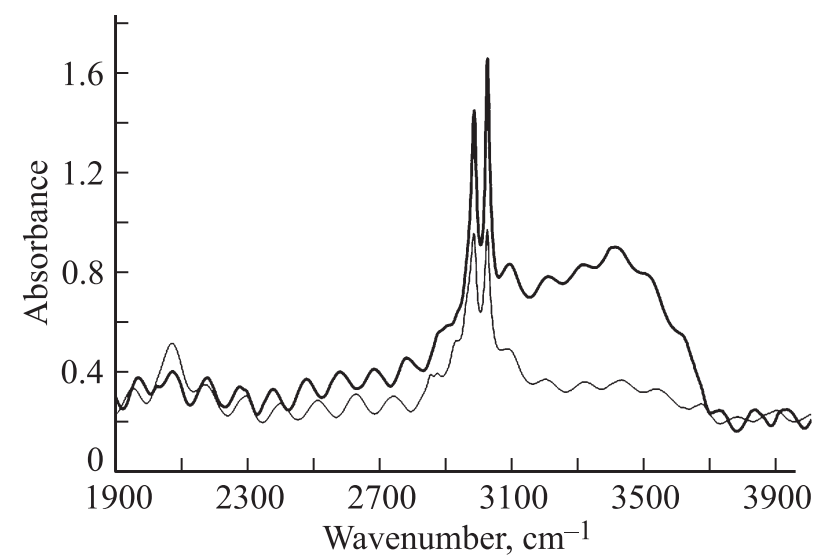

Рис. 5. ИК-спектры поглощения образцов № 5 и 7 (жирная и тонкая линии соответственно) в интервале $1900-4000 \mathrm{~cm}^{-1}$.

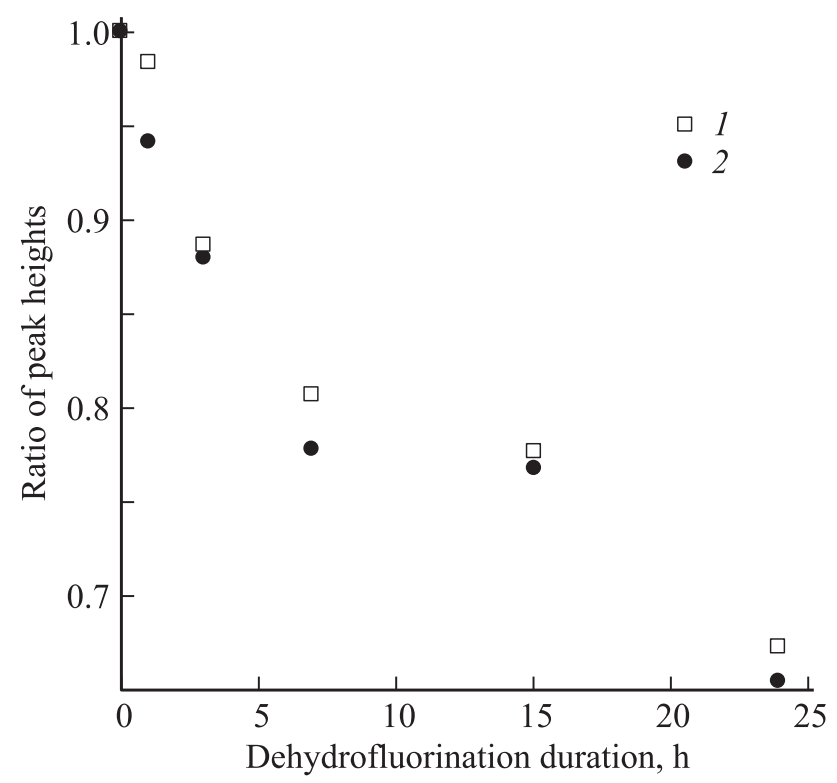

Рис. 6. Относительное изменение пиковой интенсивности полос поглощения $\delta \mathrm{CF}_{2}+\delta \mathrm{CCC}\left(765 \mathrm{~cm}^{-1}\right)$ (1) и $r \mathrm{CH}_{2}$ $\left(796 \mathrm{~cm}^{-1}\right)(2)$ в процессе ДГФ. лах $1500-1800$ и $2400-3700 \mathrm{~cm}^{-1}$. Первый из них соответствует резонансным частотам продольных колебаний двойных углерод-углеродных и углерод-кислородных связей [2], а также деформационных колебаний молекул воды [11]. Второй, как отмечалось выше, отвечает частотам валентных колебаний ОН-групп. Соответствующие фрагменты спектров представлены на рис. 4 и 5. Обращает на себя внимание корреляция между максимальными значениями оптической плотности для различных образцов в первом интервале и при $3400 \mathrm{~cm}^{-1}$. Этот факт, скорее всего, является свидетельством присутствия в карбонизированном слое химически несвязанной воды и ее удаления при отжиге. Тем не менее непропорциональность уменьшения двух обсуждаемых полос поглощения при отжиге до $270^{\circ} \mathrm{C}$, очевидная при сравнении рис. 3 и 5, подтверждает, что доминирующий вклад в резонансное поглощение ИК-излучения в диапазоне $1500-1800 \mathrm{~cm}^{-1}$ вносят не молекулы воды, а колебания связей $\mathrm{C}=\mathrm{C}$ и $\mathrm{C}=\mathrm{O}$.

Еще одна слабая, но вызывающая интерес полоса поглощения, наблюдаемая лишь в спектрах образцов № 3 и 7 (рис. 4 и 5), локализована вблизи $2000-2100 \mathrm{~cm}^{-1}$ и, по-видимому, обусловлена колебаниями тройных углерод-углеродных связей. Наконец, анализ этих же рисунков демонстрирует уменьшение вклада антисимметричных валентных колебаний связей $\mathrm{CH}_{2}\left(3026 \mathrm{~cm}^{-1}[13]\right)$, что отражает формирование фрагментов углеродных цепей полиенового типа.

На рис. 6 представлена зависимость пиковых величин оптической плотности полос поглощения при 765 и $796 \mathrm{~cm}^{-1}$, обусловленных колебаниями $\mathrm{CF}_{2^{-}}$и $\mathrm{CH}_{2}$-групп соответственно, от продолжительности ДГФ. Соответствующие величины в спектре образца № 1 условно приняты за единицу. Из рисунка видно, что убывание $\mathrm{CF}_{2^{-}}$и $\mathrm{CH}_{2}$-групп происходит практически синхронно, что подтверждает справедливость известной модели ДГФ $[4,6]$. В течение $24 \mathrm{~h}$ ДГФ содержание и тех, и других групп, имевшихся изначально, уменьшается примерно на треть. Этот факт свидетельствует о том, что значительная часть полимерного вещества остается в первозданном, некарбонизированном состоянии.

Рис. 7 иллюстрирует рост оптической плотности при $3400 \mathrm{~cm}^{-1}$, пропорциональной концентрации ОН-групп в образцах, при увеличении продолжительности ДГФ. Как видно из рисунка, увеличение содержания ОН-групп происходит с максимальной скоростью при малых продолжительностях реакции, затем наблюдается тенденция к замедлению. Термическая обработка существенно уменьшает количество ОН-групп в образце № 7 по сравнению с таковым для образца № 5 и несколько усложняет форму ИК-спектра в интервале $1500-1800 \mathrm{~cm}^{-1}$ (рис. 3) за счет появления дополнительной особенности при $1530 \mathrm{~cm}^{-1}$. Первый эффект, скорее всего, связан с удалением молекул воды из частично дегидрофторированного слоя вещества при термической обработке. Для выяснения природы дополнительного спектрального экстремума необходимо 
проведение специальных исследований. Спектры карбонильных соединений (альдегидов, кетонов, карбоновых кислот и их производных) характеризуются интенсивным поглощением в более высокочастотной области $1580-1900 \mathrm{~cm}^{-1}[15]$, и поэтому объяснить данную особенность не могут. Интересным представляется тот факт, что в ИК-спектре этого же образца, зарегистрированном в режиме нарушенного полного внутреннего

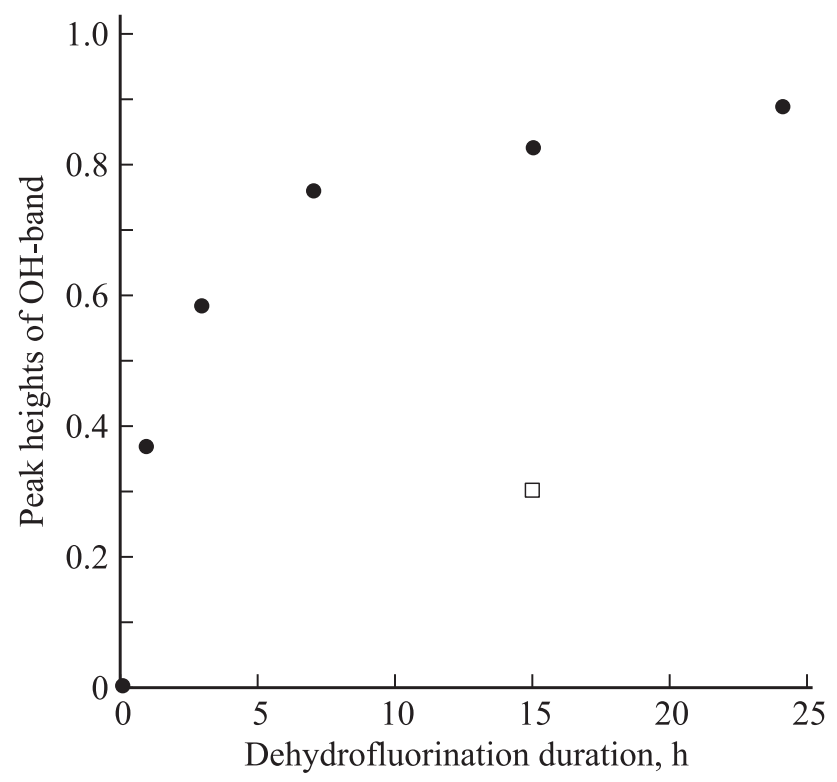

Рис. 7. Зависимость пиковой интенсивности полос ОН-групп в области $2400-3700 \mathrm{~cm}^{-1}$ от продолжительности ДГФ. Светлым квадратом обозначены данные для термически обработанного образца.

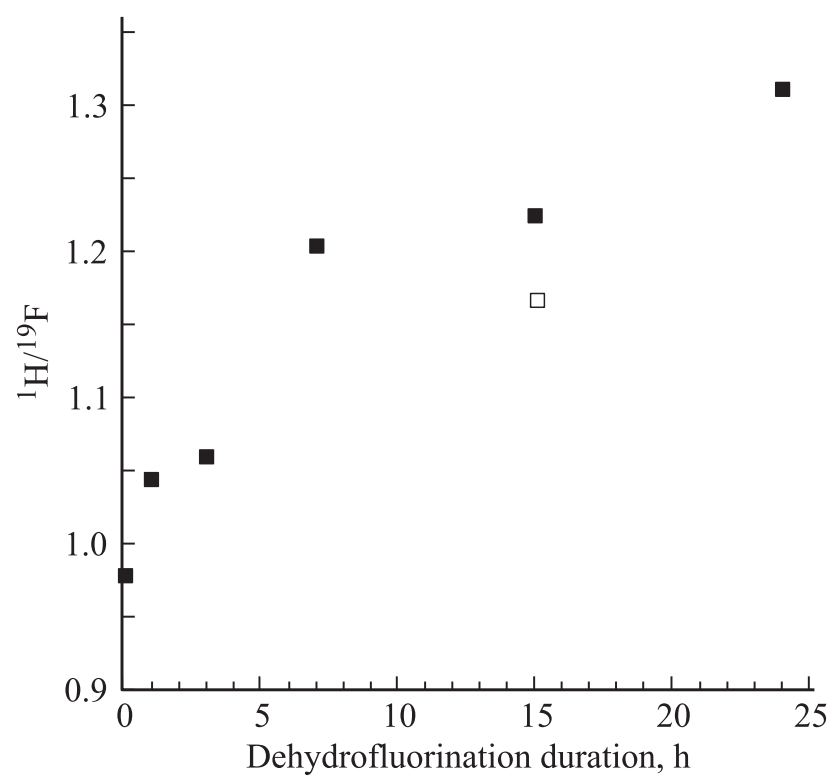

Рис. 8. Зависимость отношения концентраций атомов водорода и фтора от продолжительности ДГФ. Светлым квадратом обозначены данные для образца, подвергавшегося термической обработке.
Отношения количества атомов $\mathrm{H}$ в дегидрофторированных образцах № 2-6 к количеству атомов фтора в исходном образце № $1\left(\mathrm{~F}_{0}\right)$

\begin{tabular}{c|c|c|c|c|c|c}
\hline \multirow{2}{*}{$\begin{array}{c}\text { Продолжительность } \\
\text { ДГФ,h }\end{array}$} & \multicolumn{6}{|c}{ Номер образца } \\
\cline { 2 - 7 } & 1 & 2 & 3 & 4 & 5 & 6 \\
\cline { 2 - 7 } & 0 & 1 & 3 & 7 & 15 & 24 \\
\hline $\mathrm{H} / \mathrm{F}_{0}$ & 0.98 & 1.02 & 0.93 & 0.96 & 0.96 & 0.88
\end{tabular}

отражения, обсуждаемая особенность отсутствует, и соответственно она не может быть следствием какого-либо поверхностного загрязнения.

На рис. 8 приведена зависимость отношения концентрации атомов водорода к концентрации атома фтора от продолжительности ДГФ, выявленная при измерениях образцов № 1-7 методом ЯМР. Она хорошо коррелирует с изменениями оптической плотности при $3400 \mathrm{~cm}^{-1}$, представленными на рис. 7. С увеличением продолжительности синтеза это отношение возрастает, но скорость роста замедляется. Термическая обработка уменьшает обсуждаемый параметр. Наблюдаемая на рис. 7 и 8 корреляция свидетельствует о том, что причиной роста общей концентрации водорода при ДГФ служит появление в карбонизированном слое пленочных образцов как химически связанных, так и несвязанных ОН-групп (вода). Гидроксильные группы могут появляться в продуктах ДГФ вследствие протекания побочной реакции нуклеофильного замещения атомов фтора гидроксильными группами щелочи. Присоединение по кратным связям также возможно [6]. Вода может быть адсорбирована внутри карбонизированного слоя поверхности при промывке пленок после синтеза. Следует отметить, что в образце № 1, не подвергавшемся ДГФ, отношение концентраций атомов $\mathrm{H} / \mathrm{F}$ равно 0.98 , что несколько меньше единицы - значения, ожидаемого из химической формулы ПВДФ. Полученное несоответствие, повидимому, связано с дефектностью строения исходного полимера, имеющего в цепях включения тетрафторэтиленовых звеньев.

Попробуем оценить эффективность отсоединения атомов фтора и водорода в процессе ДГФ. Для этого используем данные рис. 6 и 8 - долю оставшихся при различных продолжительностях ДГФ $\mathrm{CF}_{2}$ - и $\mathrm{CH}_{2}$-групп и соответствующую величину $\mathrm{H} / \mathrm{F}$ - для нахождения отношения количества атомов Н в дегидрофторированных образцах № 2-6 к количеству атомов фтора в исходном образце № $1\left(\mathrm{~F}_{0}\right)$. Полученные с помощью этого расчета результаты представлены в таблице.

Анализ данных таблицы показывает, что на ранней стадии ДГФ (до $1 \mathrm{~h}$ ) общее количество водорода в образце № 2 несколько увеличивается: его убыль за счет уменьшения количества $\mathrm{CH}_{2}$-групп, по-видимому, перекрывается присоединением ОН-групп к углеродному скелету в местах отщепления не только атомов 
водорода, но и атомов фтора. При увеличении продолжительности ДГФ растет число кратных углеродуглеродных связей, в результате чего возможность протекания реакций замещения фтора сильно ограничивается. Это приводит к замедлению скорости возрастания числа ОН-групп и даже заметному уменышению общего количества водорода в образце № 6 по сравнению с имеющим место в исходном полимере. Следует также отметить возможность вклада этокси-групп растворителя (этанола) в побочных реакциях замещения [6].

\section{4. Заключение}

Химическое ДГФ ПВДФ приводит к образованию на поверхности ПВДФ обогащенного углеродом слоя, содержащего одномерные фрагменты. Присоединение к углеродному скелету ОН-групп препятствует образованию протяженных фрагментов с доминированием кратных углерод-углеродных связей. На ранних стадиях ДГФ (до 3 h) убыль метиленовых групп может компенсироваться присоединением гидроксильных групп к углеродному скелету. При увеличении продолжительности ДГФ растет число кратных углерод-углеродных связей, в результате чего возможность такого присоединения ограничивается. Это приводит к замедлению скорости увеличения числа ОН-групп.

Анализ влияния отжига на форму ИК-спектров показал, что доминирующий вклад в резонансное поглощение в диапазоне $1500-1800 \mathrm{~cm}^{-1}$ вносят не молекулы воды, а колебания связей $\mathrm{C}=\mathrm{C}$ и $\mathrm{C}=\mathrm{O}$-связей. Термическая обработка химически дегидрофторированной в течение $15 \mathrm{~h}$ пленки ПВДФ позволяет существенно уменьшить содержание в ней ОН-групп, а также индуцирует конформационное превращение $\alpha \rightarrow \beta$ в той части полимерного вещества, которая не прореагировала со смесью после ДГФ.

\section{Список литературы}

[1] И.В. Шахова, Е.А. Беленков. ФТТ 53, 2265 (2011).

[2] R.B. Heimann, S.E. Evsyukov, L. Kavan. Carbyne and carbynoid structures. Kluwer Academic Publ., Dordrecht (1999). $446 \mathrm{p}$.

[3] Т.Г. Шумилова, Ю.В. Данилова, М.В. Горбунов, С.И. Исаенко. ДАН 436, 394 (2011).

[4] Ю.П. Кудрявцев, С.Е. Евсюков, В.Г. Бабаев. Изв. АН СССР. Сер. хим. 5, 1223 (1992).

[5] I.I. Vointseva, L.M. Gil'man, Yu.P. Kudryavtsev, S.E. Evsyukov, L.A. Pesin, I.V. Gribov, N.A. Moskvina, V.V. Khvostov. Eur. Polym. J. 32, 61 (1996).

[6] С.Е. Евсюков, Ю.П. Кудрявцев, Ю.В. Коршак. Успехи химии 60, 764 (1991).

[7] А.А. Волегов, Л.А. Песин, И.Г. Маргамов, С.Е. Евсюков, О.В. Корякова, В.А. Кочедыков. Изв. Челяб. науч. центра 34, 26 (2006).

[8] Н.А. Мавринская, Л.А. Песин, М. Баумгартен, Е.М. Байтингер, А.В. Мавринский, С.Е. Евсюков. Вест. ЮУрГУ 107, 7, 80 (2008).
[9] Н.А. Мавринская, А.В. Мавринский, М. Баумгартен, Е.М. Байтингер, С.Е. Евсюков, Л.А. Песин. Вест. ЮУрГУ 122, 22, 88 (2008).

[10] В.Е. Живулин, Л.А. Песин, В.М. Морилова, О.В. Корякова. Вест. ЮУрГУ. Сер. Математика. Механика. Физика 6, 2, 56 (2014).

[11] Т.И. Шишелова, Т.В. Созинова, А.Н. Коновалова. Практикум по спектроскопии. Вода в минералах. Академия естествознания, М. (2010). 88 с.

[12] В.Д. Федотов, Х. Шнайдер. Структура и динамика полимеров. Исследование методом ЯМР. Наука, М. (1992). 208 с.

[13] В.В. Кочервинский. Успехи химии 65, 936 (1996).

[14] В.М. Морилова, С.Е. Евсюков, О.В. Корякова, В.П. Андрейчук, Л.А. Песин. Вест. ЮУрГУ. Сер. Математика. Механика. Физика 4, 95 (2011).

[15] Н.А. Хайруллина, М.Н. Соколова, И.Г. Маргамов, С.Е. Евсюков, Л.А. Песин. Изв. Челяб. науч. центра 30, 1 (2005). 